\title{
TRANSFORMATION OF THE MECHANISM OF STATE SUPPORT OF AGRICULTURE WITH THE USE OF THE PROJECT MANAGEMENT TOOL \\ Abstract
}

The article analyzes the existing system of state support for the agro-industrial complex of the Russian Federation, explores its development trends and proposes to transform the support mechanism for business entities through the formation of an integrated system for creating and implementing priority projects in the agricultural sector with the participation of flexible integration associations. The proposed approach can become the basis for the development of priority areas, uniting around itself mutually beneficial all interested economic entities.

Keywords: agro-industrial complex, state regulation of the economy, state support for the agro-industrial complex, state program, national project, priority project, project management, project activity, subsidy, business entity, flexible integration association.

\section{References}

1. Il'ichev A.V. Osnovy analiza effektivnosti i riskov celevyh programm. Istoki, formalizaciya, realizaciya. M.: Nauchnyj mir, 2009. 332 p.

2. SHed'ko YU.N. Programmno-celevoj metod kak instrument povysheniya effektivnosti territorial'nyh socioekonomicheskih sistem // Regional'naya ekonomika: teoriya i praktika. 2010. № 44 (179). P. 24 - 30.

3. Samaruha V.I., Sorokina T.V. Primenenie programmno-celevogo metoda v finansovom obespechenii byudzhetnogo sektora regiona // Izvestiya Irkutskoj ekonomicheskoj akademii. 2013. №.3. [Elektronnyj resurs]. Rezhim dostupa: URL: http://eizvestia.isea.ru/ (data obrashcheniya: 29.09.2018).

4. Granberg A.G. Osnovy regional'noj ekonomiki. M.: GU-VSHE, 2001. 495 s.

5. Glaz'ev S.YU., Batchikov S.A. Effektivnost' gosudarstvennogo upravleniya. Pod obshchej red. S.YU. Glaz'eva. M.: Fond Za ekonomicheskuyu gramotnost', Rossijskij ekonomicheskij zhurnal, Izd-vo 000 Konsaltbankir, 1998. 848 p.

6. Bilev O. Proektnyj podhod v gosudarstvennom upravlenii: opyt, problematika i perspektivy. Oficial'nyj sajt centra proektnogo menedzhmenta RANHiGS [Elektronnyj resurs]. Rezhim dostupa: URL: https://pm.center/library/prezentatsii-i-doklady/ (data obrashcheniya 15.12.2019).

7. Balashov A.P. Osnovy menedzhmenta. M.: Vuzovskij uchebnik, INFRA-M, 2020. 288 p.

\section{ИНСТРУМЕНТЫ ЦИФРОВОЙ ЭКОНОМИКИ В КОНТЕКСТЕ ИХ ВЛИЯНИЯ НА ЭФФЕКТИВНОСТЬ ФАРМАЦИИ}

Вардомацкая
Людмила
Петровна
Лилюхин
Андрей
Михайлович

Вардомацкая

кандидат экономических наук, доцент, Ростовский государственный медицинский университет (344022, Россия, г. Ростов-на-Дону, пер. Нахичеванский, 29). E-mail: econandsociologyRostGMU@yandex.ru кандидат социологических наук, доцент, Ростовский государственный медицинский университет (344022, Россия, г. Ростов-на-Дону, пер. Нахичеванский, 29). E-mail: econandsociologyRostGMU@yandex.ru

\section{Аннотация}

Изучаются необходимость и возможность использования технологий цифровой экономики и инструментов их реализации в здравоохранении, в частности, фармации. Исследуются особенности использования в фармацевтической отрасли таких инструментов цифровой экономики, как блокчейн, большие данные, искусственный интеллект, интернет вещей. Изучение возможности применения технологий цифровой экономики и их инструментов позволяет сделать выводы о реальных перспективах уменьшения трудозатрат, снижения стоимости производства и доставки лекарственных средств, невозможности реализации на фармацевтическом рынке поддельных и контрафактных лекарственных средств.

Ключевые слова: цифровая экономика, экономические отношения цифровой экономики, социальная сфера, фармация, инструменты технологий цифровой экономики, блокчейн, большие данные, искусственный интеллект, интернет вещей.

Здравоохранение представляет собой одну из важнейших отраслей социальной сферы, способствующей обеспечению безопасности страны, росту её экономики, повышению качества жизни. К сфере здравоохранения в соответствии с функционально-институциональным признаком, определяющим тип медицинской организации, относятся фармацевтические предприятия, объединенные общим понятием «фармация» [1]. Основные виды деятельности фармации заключаются в изучении 
потребностей в лекарственных средствах, научных исследованиях в области фармакологии, создании, изготовлении лекарственных средств, их апробации в клинических условиях и реализации, оказании образовательных фармацевтических услуг. Об экономическом значении фармации свидетельствует факт вхождения России в первую десятку фармацевтических рынков мира. Его емкость, определяемая стоимостным показателем реализованных лекарственных средств, в 2018 г. составила 1682 млрд руб. ${ }^{1}$

Приоритетным направлением развития экономики России сегодня становится внедрение цифровых технологий, открывающих впечатляющие перспективы в развитии страны. Внедрение небывалых форматов в управление и переход к цифровой экономике - важнейшие приоритеты страны в долгосрочной перспективе2 ${ }^{2}$ в связи с чем поставлена задача обеспечить информационное развитие здравоохранения посредством создания и эксплуатации информационных систем медицинских и фармацевтических организаций ${ }^{3}$.

Информационная экономика, пройдя ряд стадий в своем развитии (создания и использования мейнфреймов, персональных компьютеров, Интернет, мобильных передающих устройств), на основе использования новых парадигм вычислений вышла на более высокую ступень своего развития цифровую экономику.

Существует трактовка цифровой экономики как хозяйственной деятельности, основанной на использовании предприятиями всей необходимой информации в цифровом виде, что позволяет анализировать огромные массивы цифровых данных ${ }^{4}$, это было невозможно при существовавших раннее технологиях работы с информацией.

Цифровая экономика здравоохранения - это экономические отношения производства, распределения, обмена и потребления, в процессе которых анализируются, перерабатываются и используются огромные массивы данных здравоохранения в цифровой форме на основе новейших технологий. Технологии цифровой экономики становятся главным фактором производства, преобразуя все экономические взаимосвязи и минимизируя участие в них человека.

Здравоохранение уже постепенно становится цифровым. Так, на фармацевтическом рынке online-продажи рецептурных препаратов составляют $43 \%$, а безрецептурных - $57 \%$.

Цифровые технологии предполагают наличие определенных инструментов их использования. Под инструментом понимается метод воздействия на исследуемый объект с целью получения определенного результата.

Рассмотрим основополагающие инструменты цифровой экономики, возможности и последствия их использования в фармации.

1. Блокчейн. Это цепочка блоков информации, которая не хранится на одном сервере и не управляется централизованно, а отражается (дублируется) на множестве компьютеров [2]. Блокчейн охватывает всю информацию о материальном продукте или услуге на всех стадиях производства, где каждый блок данных связан с предыдущим и последующим с помощью набора алгоритмов, насчитывающих не менее 60 символов. Каждый блок имеет ссылку на предыдущий с обозначением времени создания документа, изменить который невозможно ни по содержанию, ни по времени внесения [3].

В программном обеспечении, установленном на подавляющем числе компьютеров, вносимые информационные данные хранятся в базах, не связанных между собой и имеющих уязвимое место: они

\footnotetext{
1 Фармацевтический рынок в 2018 году [Электронный ресурс] - Режим доступа:

http://GMPnews.ru>2019/05/obzor_rynka-rosü-v-2018godu (дата обращения 07.06. 2019)

2 Распоряжение Правительства РФ от 28 июля 2017 г. №1632-р «Об утверждении программы « Цифровая экономика Российской Федерации». «Программа «Цифровая экономика Российской Федерации». [Электронный ресурс] Режим доступа: http://statik.government.ru/media/files/9GFM4EHj4PsB7915v7yLVuPgu4bvR7MO.pdf (дата обращения 05. 05. 2019 г.).

3 Федеральный закон от 29 июня 2017 года № 242 «0 внесении изменений в отдельные законодательные акты Российской Федерации по вопросам применения информационных технологий в сфере охраны здоровья». Российская газета - федеральный выпуск №7338. 4 августа 2017 г.

${ }^{4}$ См. Указ Президента РФ от 9 мая 2017 года N203 «0 стратегии развития информационного общества в Российской Федерации на 2017 - 2030 годы» [Электронный ресурс] - Режим доступа (www.kremlin.ru/acts/bank/41919).

${ }^{5}$ Стратегия цифровизации как способ организации взаимодействия с конечными потребителями. Тенденции фармакологического рынка России - 2018. Исследовательский центр компании «Делойт» в СНГ. Москва. 2018. 41 с. [Электронный ресурс] - Режим доступа: https://www2.deloitte.com/content/dam/Deloitte/ru/Documents/life-sciences-health-care/russian/russianpharmaceutical-market-trends-2018.pdf (дата обращения: 15.12.2019)
} 
могут подвергаться корректировке и хакерским атакам. В технологии блокчейн последнее исключается вследствие невозможности переработать огромный массив символов, заключенных в криптошифровании блоков информации [4]. Все операции в поле зрения участников и не могут быть изменены.

Блокчейн характеризуется следующими особенностями:

- невозможностью внесения некорректных данных. Все участники сети в постоянном режиме проверяют правильность внесения данных всеми участниками сети;

- равноправие, то есть каждый участник сети имеет такие же права, как и другие;

- распределение информации среди большого числа участников, отсутствие единого сервера для хранения данных. Это приводит к невозможности осуществления контроля над информацией участников транзакций;

- конфиденциальность. Внесенная в цепочку блоков информация может быть прочитана лишь владельцем, который обладает для этого закрытым ключом криптошифрования;

- устойчивость к Ddos-атакам [5].

Особенности блокчейна создают возможности его использования для просмотра всей цепочки продвижения лекарственных средств от производителя к потребителю. Это важно в условиях, когда рынок поддельных и контрафактных лекарств составляет около 30 млрд., вследствие чего пациенты медицинских организаций могут не получить необходимого лечения и в лучшем случае не почувствуют положительных результатов лечения [6].

Используя блокчейн, пациенты клинических отделений медицинских организаций с помощью закрытого электронного ключа шифрования протокола лечения, доступного только владельцу информации, смогут осуществлять контроль за правильностью его применения, в том числе контролировать предоставление лекарств, назначенных врачом. Это исключит подмену дорогостоящих лекарственных средств, купленных за бюджетные деньги, и их реализацию на стороне.

В настоящее время в некоторых регионах страны уже используется маркировка лекарств специальным чипом, позволяющем защитить рынок лекарственных средств от подделок. Наличие чипа позволяет отличить настоящее лекарство от поддельного с помощью специального недорого электронного устройства. Эта манипуляция по силам не только специалистам, но и покупателям лекарственных средств.

2. Большие данные. Появление термина связано с ежегодным возрастанием огромного количества информации, требующей переработки и осмысления, массива данных, которые невозможно переработать и проанализировать, используя традиционные методы. Таким образом, объектом изучения являются большие объемы цифровой информации, поступающей из сети Интернет и других источников из различных областей социально-экономической жизни в том числе сферы здравоохранения.

Использование Больших данных (big data) в фармации связано с необходимостью проведения клинических испытаний препарата перед запуском его в серийное производство. Для этого необходимо сформировать группы людей, согласных на проведение таких испытаний с целью выявления как негативных побочных эффектов, так и эффективности испытываемого лекарственного средства. Такие группы людей, помимо их желания участвовать в клиническом доведении препарата до серийного производства, должны обладать и необходимыми, специфическими параметрами состояния здоровья. Получить и проанализировать такую информацию помогают большие блоки информации о кандидатах на испытание, источником которых являются записи в электронных медицинских картах, а также информация о предыдущих участниках клинических испытаний, хранящаяся и накапливаемая путем использования технологии блокчейн.

Большие данные используются также в прецизионной фармацевтике, когда фармацевтические компании и научно-исследовательские подразделения фармацевтических вузов с разрешения пациентов, используя сведения об их состоянии здоровья, полученных из электронных карт историй болезней, формируют фармакотерапевтические группы для производства лекарств специально для таких групп пациентов. Получение информации о геноме пациентов значительно увеличивает возможность производства лекарственных средств целенаправленного действия, а следовательно более эффективных.

Новые перспективы в использовании Больших данных открывает кластерная организация предприятий здравоохранения, объединяющая медицинские и фармацевтические организации в целях повышения эффективности их функционирования за счет синергетического эффекта агрегированной структуры кластера [7]. В рамках кластера расширяются возможности доступа его научно-исследовательского звена к записям в электронных медицинских картах, характеризующих те или иные заболевания пациентов с целью формирования блоков информации научных разработок для создания инновационных лекарственных средств. 
Большие данные в сочетании с блокчейном способны сформировать кластерные экосистемы в области научных разработок, начиная с изучения потребностей здравоохранения в новых лекарственных средствах, производства экспериментальных образцов и заканчивая клиническими испытаниями.

Большие перспективы открываются в связи с возможностями использования технологии Віg Data для применения математических методов моделирования процессов органического синтеза лекарственных средств, что приводит к существенному их удешевлению. Так, стоимость синтеза препарата «Дараприм», используемом для лечения ВИЧ-инфицированных, была снижена до 25 центов, в то время как в недалеком прошлом производитель этого препарата инвестиционная группа MSMB Capital Management (США) продавала этот препарат за 750\$ за дозу1.

3. Интеллектуальные информационные технологии. Имеется в виду, прежде всего искусственный интеллект, который в состоянии рассматривать различные проблемы в виде формальной системы, описывать их, моделировать и обрабатывать путем использования определенных алгоритмов [8; 9].

Особенностью искусственного интеллекта является способность к самообразованию и развитию, что способствует более быстрому решению проблем в различных сферах жизни.

В настоящее время крупнейшие фармацевтические кампании мира, такие, как Jonson \& Jonson, Sanofi, Merk \& Co инвестируют в искусственный интеллект значительные суммы, проводя эксперименты по использованию искусственного интеллекта для разработки новых лекарственных средств. Особенно выделяется такое направление экспериментов, как создание лекарств для конкретных пациентов, исключающих нежелательные для них побочные эффекты и гарантирующих более успешное лечение заболеваний по сравнению с обычными лекарствами.

Широкое внедрение искусственного интеллекта в фармацевтическую отрасль способно в корне изменить способы производства лекарственных средств, их полезный эффект и стоимость.

4. Интернет вещей. С помощью блокчейна возможно создание самоуправляющихся систем, в которых составляющие их объекты будут взаимосвязаны, и управляться с помощью несложных устройств. Самоуправляющиеся объекты образуют интернет вещей, под которым подразумевается сеть физических объектов, которые действуют самостоятельно в процессе передачи информации, взаимодействующие друг с другом и внешней средой без участия человека. Для выполнения актов взаимодействия объекты сети необходимо унифицировать, разбив на подгруппы, которые способны участвовать в автоматических транзакциях в соответствии с запрограммированными целями.

Лекарственные средства поддаются унификации на основе их фармакотерапевтических свойств. На основе специальных программ, возможно их использование как самоуправляемых активов, которые будут заказывать необходимые медикаменты, и осуществлять их реализацию, используя для этого информацию, полученную на основе заключенных контрактов с поставщиками и клиентами, либо из внешних источников. Аптека может использовать встроенную программу, которая автоматически совершает заключение «умных контрактов» на поставку как уже апробированных лекарственных средств, так и новых после успешных клинических испытаний.

Степень использования рассмотренных инновационных инструментов цифровой экономики характеризуют следующие данные:

- передовые системы учета составляют 50 \%;

- облачные технологии - 38 \%;

- большие данные (Big Data) - $6 \%$;

- блокчейн - $4 \%$;

- Smart-производство - $4 \%$;

- искусственный интеллект - 2 \%.

Фармацевтические компании, как свидетельствуют приведенные данные, находятся в самом начале пути освоения новейших цифровых технологий. Однако каждая пятая компания планирует их внедрять. Лидирующие позиции по внедрению стратегии диджитализации занимают российские и иностранные компании с мобилизацией производства в России (30-31\%)․

\footnotetext{
1 Цифровизация как драйвер глобальных изменений рынка фармацевтики. [Электронный ресурс] - Режим доступа: URL: http://xn--80aplem.xn--p1ai/analytics/Cifrovizacia-kak-drajver-globalnyh-izmenenijrynka-farmacevtiki/ (дата обращения: 30.02.2020)

2 Стратегия цифровизации как способ организации взаимодействия с конечными потребителями. Тенденции фармакологического рынка России - 2018. Исследовательский центр компании «Делойт» в СНГ. Москва. - 2018. - 41 с. [Электронный ресурс] - Режим доступа:

https://www2.deloitte.com/content/dam/Deloitte/ru/Documents/life-sciences-health-care/russian/russianpharmaceutical-market-trends-2018.pdf (дата обращения: 15.12.2019)
} 
Рассмотрев перспективы использования цифровой экономики в фармацевтической отрасли, можно сделать выводы о том, что внедрение ее инструментов позволит:

- перевести весь документооборот предприятий фармацевтической отрасли на блокчейн. Это обеспечит прозрачность прохождения логистической цепочки от производителя к потребителю и застрахует последних от поддельных и контрафактных лекарств;

- перейти к осуществлению цифровых контрактов и безбумажных сделок, что снизит стоимость производства и доставки лекарств;

- ускорить разработку новых лекарственных средств на основе использования Больших данных о состоянии здоровья пациентов путем формирования фармакотерапевтических групп для производства лекарственных средств именно для таких групп;

- существенно изменить способы производства лекарственных средств и их полезный эффект на основе внедрения в фармацевтическую отрасль искусственного интеллекта;

- сократить трудозатраты и повысить эффективность использования средств, выделенных на логистику фармацевтической продукции путем использования «интернета вещей».

В недалеком будущем страны-лидеры цифровизации получат неоспоримые конкурентные преимущества на мировом рынке.

\section{Литература}

1. Управление и экономика фармации / Под ред. И.А. Наркевича М.: ГЭОТАР - Медиа, 2018.928 с.

2. Nurbayev A. Технология блокчейн в медицине: зачем и кому это нужно [Электронный ресурс] Режим доступа://http3://crypto24.ru/blokchein-tehnologii/blokchein-v-meditsine (дата обращения 15. 05. 2019 г.).

3. Кузнецова В.П., Вардомацкая Л.П., Тропинова Е.А. Блокчейн в здравоохранении // Экономика и управление. 2018. № 7 (153). С. 17.

4. Пряников М.M., Чугунов А.В. Блокчейн как коммуникационная основа формирования цифровой экономики: преимущества и проблемы // International journal of open Information Technologies. ISSN: 2307-81-62. Vol.5. № 6. 2017. С. 49-51.

5. Вардомацкая Л.П. Перспективы использования цифровых технологий в научно-образовательном инновационном медицинском кластере // Гуманитарные и социально-экономические науки. 2019. № 2. С. 138.

6. Вардомацкая Л.П. Инновационная маркетинговая стратегия организации фармацевтического рынка // Journal of Economic Regulation (Вопросы регулирования экономики). Т. 9 (3). 2018.

7. Кузнецова В.П., Вардомацкая Л.П. Научно-образовательный медицинский кластер как агрегированная структура экономики здравоохранения // Государственное и муниципальное управление. Ученые записки. 2019. № 2. С. 110 - 115.

8. Истомина Т. В., Дунин В. О., Егоров В. А. Проектирование и разработка интеллектуальной информационной системы поддержки медицинских учреждений // XXI век: итоги прошлого и проблемы настоящего плюс. 2014. №1 (17). С. 184 - 190.

9. Садыкова Р. Ш., Абдуллина Л. А., Газизуллина Л.И. Инновационные технологии в нефтяной промышленности: интеллектуальное оснащение скважин // Актуальные проблемы экономики и права. 2013. № 2. С. $94-100$.

Vardomatskaya Lyudmila Petrovna, Candidate of Economic Sciences, Associate Professor, Rostov state medical University (29, Nakhichevansky lane, Rostov-on-Don, 344022, Russian Federation).

E-mail: econandsociologyRostGMU@yandex.ru

Lilyukhin Andrey Mikhailovich, Candidate of Sociological Sciences, Rostov state medical University (29, Nakhichevansky lane, Rostov-on-Don, 344022, Russian Federation).

E-mail: econandsociologyRostGMU@yandex.ru

\section{DIGITAL ECONOMY TOOLS IN THE CONTEXT OF THEIR IMPACT ON PHARMACEUTICAL EFFICIENCY \\ Abstract}

The necessity and possibility of using digital economy technologies and tools for their implementation in healthcare, in particular, pharmacy, are Studied. The features of using such digital economy tools as blockchain, big data, artificial intelligence, and the Internet of things in the pharmaceutical industry are studied. The study of the possibility of using technologies in the digital economy and their tools allows us to draw conclusions about the real prospects of reducing labor costs, reducing the cost of production and delivery of medicines, the impossibility of selling counterfeit and counterfeit medicines on the pharmaceutical market. 
Keywords: digital economy, economic relations of the digital economy, social sphere, pharmacy, tools of digital economy technologies, blockchain, big data, artificial intelligence, Internet of things.

\title{
References
}

1. Upravlenie i ekonomika farmacii / Pod red. I.A. Narkevicha M.: GEOTAR - Media, 2018. 928 p.

2. Nurbayev A. Tekhnologiya blokchejn v medicine: zachem i komu eto nuzhno [Elektronnyj resurs] - Rezhim dostupa://http3://crypto24.ru/blokchein-tehnologii/blokchein-v-meditsine (data obrashcheniya 15. 05. 2019 g.).

3. Kuznecova V.P., Vardomackaya L.P., Tropinova E.A. Blokchejn v zdravoohranenii // Ekonomika i upravlenie. 2018. № 7 (153). P. 17.

4. Pryanikov M.M., CHugunov A.V. Blokchejn kak kommunikacionnaya osnova formirovaniya cifrovoj ekonomiki: preimushchestva i problemy // International journal of open Information Technologies. ISSN: 2307-81-62. Vol.5. № 6. 2017. P. 49-51.

5. Vardomackaya L.P. Perspektivy ispol'zovaniya cifrovyh tekhnologij v nauchno-obrazovatel'nom innovacionnom medicinskom klastere // Gumanitarnye i social'no-ekonomicheskie nauki. 2019. № 2. P. 138.

6. Vardomackaya L.P. Innovacionnaya marketingovaya strategiya organizacii farmacevticheskogo rynka // Journal of Economic Regulation (Voprosy regulirovaniya ekonomiki). T. 9 (3). 2018.

7. Kuznecova V.P., Vardomackaya L.P. Nauchno-obrazovatel'nyj medicinskij klaster kak agregirovannaya struktura ekonomiki zdravoohraneniya // Gosudarstvennoe i municipal'noe upravlenie. Uchenye zapiski. 2019. № 2. P. 110 - 115.

8. Istomina T. V., Dunin V. O., Egorov V. A. Proektirovanie i razrabotka intellektual'noj informacionnoj sistemy podderzhki medicinskih uchrezhdenij // XXI vek: itogi proshlogo i problemy nastoyashchego plyus. 2014. №1 (17). P. $184-190$.

9. Sadykova R. SH., Abdullina L. A., Gazizullina L.I. Innovacionnye tekhnologii v neftyanoj promyshlennosti: intellektual'noe osnashchenie skvazhin // Aktual'nye problemy ekonomiki i prava. 2013. № 2. P. 94 - 100.

\section{ПЕРСПЕКТИВЫ ИСПОЛЬЗОВАНИЯ СЕВЕРНОГО МОРСКОГО ПУТИ В МЕЖДУНАРОДНОЙ ТРАНСПОРТНОЙ СИСТЕМЕ}

\author{
Волков кандидат экономических наук, доцент кафедры международных \\ Геннадий экономических отношений, Южно-Российский институт управления - \\ Юрьевич \\ службы при Президенте РФ (344002, Россия, г. Ростов-на-Дону, \\ ул. Пушкинская, 70/54). E-mail: gwolkow061@rambler.ru
}

\section{Аннотация}

В статье анализируются проблемы использования Северного морского пути в качестве альтернативной транспортной магистрали по доставке грузов на европейские рынки. Рассматриваются основные природно-экономические, финансовые и другие факторы, препятствующие активной эксплуатации СМП с учетом изменений в современной геополитической обстановке, предлагаются перспективные меры по их минимизации.

Ключевые слова: Северный морской путь, ледокольный флот, морская перевозка, глобальное потепление, фрахтовая ставка, использование акватории, политика импортозамещения, освоение северных территорий, рентабельность.

Глобальные климатические изменения и необходимость перестройки экономики РФ в условиях санкционного противостояния актуализировали проблематику поиска реальных драйверов развития при переходе к политике импортозамещения. Ряд аналитиков предложили в числе реальных перспектив вариант ускоренного развития арктического региона и акватории Северного морского пути (СМП) в качестве одного из драйверов для развития российской экономики и реального конкурента Суэцкого канала. Однако однозначного подхода к данной проблематике нет, поскольку наряду со сторонниками данной альтернативы, доказывающими экономическую выгоду, рентабельность и полную окупаемость перспективного проекта, нашлись активные противники, выдвигающие не менее аргументированные доводы. Поскольку основное внимание в современной научной среде уделяется именно позитивной составляющей, проанализируем реальные проблемы в освоении северных территорий, устранение или минимизация которых в разносрочной перспективе позволит перейти к конструктивному освоению. 